\title{
Dinâmica do uso do solo e alterações na vazão na bacia do Rio São Francisco no início do Séc. XXI
}

\author{
Land use dynamics and flow changes in São Francisco river \\ basin - Brazil
}

Bruna Thomazinho França ${ }^{1}$, Marcel Pereira de Andrade $^{1}$ (D), Celso Bandeira de Melo Ribeiro ${ }^{1}$ (D), Henrique Steinherz Hippert ${ }^{1}$

${ }^{1}$ Universidade Federal de Juiz de Fora - UFJF, Juiz de Fora, MG, Brasil. E-mails: brunathomazinho@gmail.com, marcel.andrade@engenharia.ufjf.br, celso.bandeira@ufjf.edu.br, henrique.hippert@ufjf.edu.br

Como citar: França, B. T., Andrade, M. P., Ribeiro, C. B. M., \& Hippert, H. S. (2021). Dinâmica do uso do solo e alterações na vazão na bacia do Rio São Francisco no início do Séc. XXI. Revista de Gestão de Água da América Latina, 18, e11. https://doi.org/10.21168/rega.v18e11

RESUMO: Este estudo tem como objetivo avaliar as mudanças ocorridas no uso do solo na bacia hidrográfica do Rio São Francisco (BHRSF) e a influência destas mudanças nas vazões observadas no período de 2001 a 2013 . Para identificar as alterações no uso e cobertura do solo foram realizadas comparações das imagens anuais da plataforma MODIS através de um código desenvolvido no software Dinamica EGO. O produto gerado tem como informações a quantificação das mudanças em termos de área e a identificação da natureza e da localização das transições ocorridas. Para analisar a tendência no comportamento das vazões, foram utilizadas informações de 18 estações fluviométricas pertencentes à rede hidrometeorológica nacional. Aplicou-se o teste estatístico de Mann-Kendall e os resultados apontaram para transições relevantes dos tipos "Floresta para Pastagem", "Savana arborizada para Pastagem" e "Terras agrícolas para Pastagem". Observou-se também que 11 das 18 estações fluviométricas analisadas indicaram diminuição da vazão ao longo dos anos. Este resultado pode ser relacionado a elevada presença de atividades de irrigação na bacia.

Palavras-chave: Balanço Hídrico; Recursos Hídricos; Sensoriamento Remoto.

ABSTRACT: The aim of this study is to evaluate the changes occurred in the land use of São Francisco river basin (BHRSF) and their influence in the observed streamflows, during the period from 2001 to 2013. In order to identify changes in land use and land cover, images from MODIS satellite - Moderate Resolution Imaging Spectroradiometer plataform were used through a code developed in the DINAMICA EGO software. The generated product presents informations about the quantification of changes in terms of area and the identification of the type and the location of the occured transitions. To analyze the trend in streamflow behavior, 18 fluviometric stations belonging to the national hydrometeorological network, operated by ANA, were used. The Mann-Kendall statistical test was applied and the results demonstrate some significant land cover transitions, such as: "Forest to Pasture", "Woody Savanna to Savanna" and "Cropland to Savanna". It was also observed in 11 of the 18 fluviometric stations studied, a trend of decreasing streamflow over the years. This result may be explained by the large irrigation activity performed in the basin.

Keywords: Water Balance; Water Resources; Remote Sensing.

\section{INTRODUCÃO}

O desenvolvimento humano das últimas décadas tem provocado grandes alterações nas bacias hidrográficas e, portanto, questões relativas à disponibilidade hídrica têm sido amplamente debatidas. Desta forma, a devastação de florestas tropicais, prática de agricultura de subsistência, intensificação da produção agrícola e expansão de centros urbanos têm sido maneiras intensas de alteração do uso do solo provocadas pelo homem. Tais atividades são explicadas pela constante aquisição de recursos naturais para satisfazer necessidades imediatas em detrimento das condições ambientais (Foley et al., 2005). Mudanças no uso do solo são consideradas como um fator responsável pela queda dos níveis de qualidade da água. Considerando que determinadas atividades humanas exigem recursos hídricos com elevada qualidade, este assunto tem se tornado de domínio e interesse público (Mello et al., 2020).

Recebido: Março 09, 2021. Revisado: Julho 12, 2021. Aceito: Agosto 10, 2021. 
As atividades humanas se apropriam de $1 / 3$ a $1 / 2$ da produção do ecossistema global e seus serviços. Assim, diversas formas de alteração no uso do solo em escala mundial permitiram que as safras mundiais de grãos dobrassem nas últimas quatro décadas. Calcula-se que desde a década de 1960 até o início do século XXI, o uso de fertilizantes tenha aumentado em $700 \%$ e as áreas agrícolas irrigáveis em 70\% (Foley et al., 2005). Destaca-se que a forma mais representativa de uso/ocupação do solo atualmente é dada pela prática da agricultura. Essa atividade tem influência direta nas variáveis do ciclo hidrológico natural das bacias hidrográficas e é responsável pelo aporte de sedimentos, nutrientes e poluentes tóxicos para os corpos d'água (Boëchat et al., 2013; Mello et al., 2020; Pinheiro et al., 2014).

Neste sentido, a bacia hidrográfica do Rio São Francisco está situada em uma região com elevada produção agrícola e, consequentemente, com grandes quantidades de água sendo destinadas para irrigação. Esta característica tem causado mudanças no uso do solo e alterações nas vazões observadas do curso d'água (Teixeira et al., 2020). De acordo com a Agência Nacional de Águas (Brasil, 2015), a demanda hídrica para irrigação na região corresponde a cerca de $77 \%$ de toda a demanda da bacia, o que corresponde a 626 mil hectares de terras irrigadas. As localidades que mais se destacam pela agricultura irrigada são Juazeiro, Petrolina, Polo de Barreiras e sub-bacia do Rio Preto/Paracatu com a prática de atividades de fruticultura, monocultura de soja, entre outras. No estado da Bahia, os principais afluentes do rio São Francisco, rio Corrente e rio Grande, são responsáveis por suprir grande parte das demandas hídricas do local. Entretanto, devido ao aumento das atividades agrícolas na região e consequente aumento da população local, a demanda hídrica para irrigação se tornou dependente da complementação fornecida pelo aquífero Urucuia nos períodos de estiagem (Reis et al., 2020). É importante destacar que o aumento da demanda hídrica para agricultura na região ainda se agrava devido a características intrínsecas da bacia, tais como: precipitação distribuída de forma heterogênea e presença de solos rasos com baixa capacidade de armazenamento de água para suprir as demandas nos períodos de estiagem (Koch et al., 2015).

Desta forma, a Região Hidrográfica do São Francisco (RHSF) vem sofrendo com a perda da disponibilidade e da qualidade hídricas, bem como com as modificações no uso/ocupação do solo para implantação de empreendimentos industriais, urbanos e principalmente agricultura irrigada. Essas condições podem gerar tanto impactos locais como também alterar a distribuição e disponibilidade da água em toda extensão da bacia. Além do impacto no balanço hídrico da região, alguns autores destacam e investigam a interferência das alterações no uso do solo sobre os processos erosivos (Silva et al., 2016) e sobre a qualidade da água (Mello et al., 2020) na Bacia Hidrográfica do São Francisco.

Entretanto, a falta de técnicas específicas de observação e identificação da heterogeneidade do solo até a década de 1970 dificultava o processo de reconhecimento e avaliação precisa dos fenômenos ocorridos. Com a presença e evolução das ferramentas e técnicas de sensoriamento remoto inseridas nas análises, torna-se possível a detecção de mudanças no uso do solo em larga escala (Sriwongsitanon \& Taesombat, 2011). Assim, com o avanço de técnicas de sensoriamento remoto para a observação da Terra, o conhecimento técnico passou a estar associado à preocupação ambiental. Esse movimento começou a ocorrer a partir do momento em que processos de uso do solo e suas consequências passaram a ser vistos e reconhecidos de forma interdependente (Instituto Brasileiro de Geografia e Estatística, 2013). Portanto, o monitoramento espacial e temporal do uso do solo na região hidrográfica do São Francisco se torna uma ferramenta importante na mitigação dos danos provocados pelas atividades antrópicas na bacia (Silva et al., 2018).

Desta forma, este trabalho teve como objetivo avaliar mudanças no uso do solo através de técnicas de sensoriamento remoto e determinar a influência dessas alterações com mudanças observadas nas vazões registradas para a Bacia Hidrográfica do Rio São Francisco, no início do século XXI.

\section{MATERIAL E MÉTODOS}

\section{Área de estudo}

A Bacia do Rio São Francisco possui uma área de drenagem de aproximadamente $638.476 \mathrm{~km}^{2}$ que abrange um total de 521 municípios nos estados de Alagoas, Bahia, Goiás, Minas Gerais e Pernambuco, além do Distrito Federal (Brasil, 2015). De acordo com o Censo 2010 (Instituto Brasileiro de Geografia e Estatística, 2010) cerca de 14,3 milhões de pessoas habitam e fazem uso dos recursos da Bacia do São Francisco. A Figura 1 apresenta a localização, os limites e a hidrografia da bacia. 
A região hidrográfica do São Francisco pode ser dividida em quatro sub-regiões: Alto, Médio, Submédio e Baixo São Francisco. Essas regiões são definidas pelas características do clima e do ecossistema dominantes em cada local (Bezerra et al., 2019). 0 clima na região varia entre o tropical e o semi-árido com temperaturas médias variando entre $20^{\circ} \mathrm{C}$ e $26,5^{\circ} \mathrm{C}$ (Costa et al., 2017).

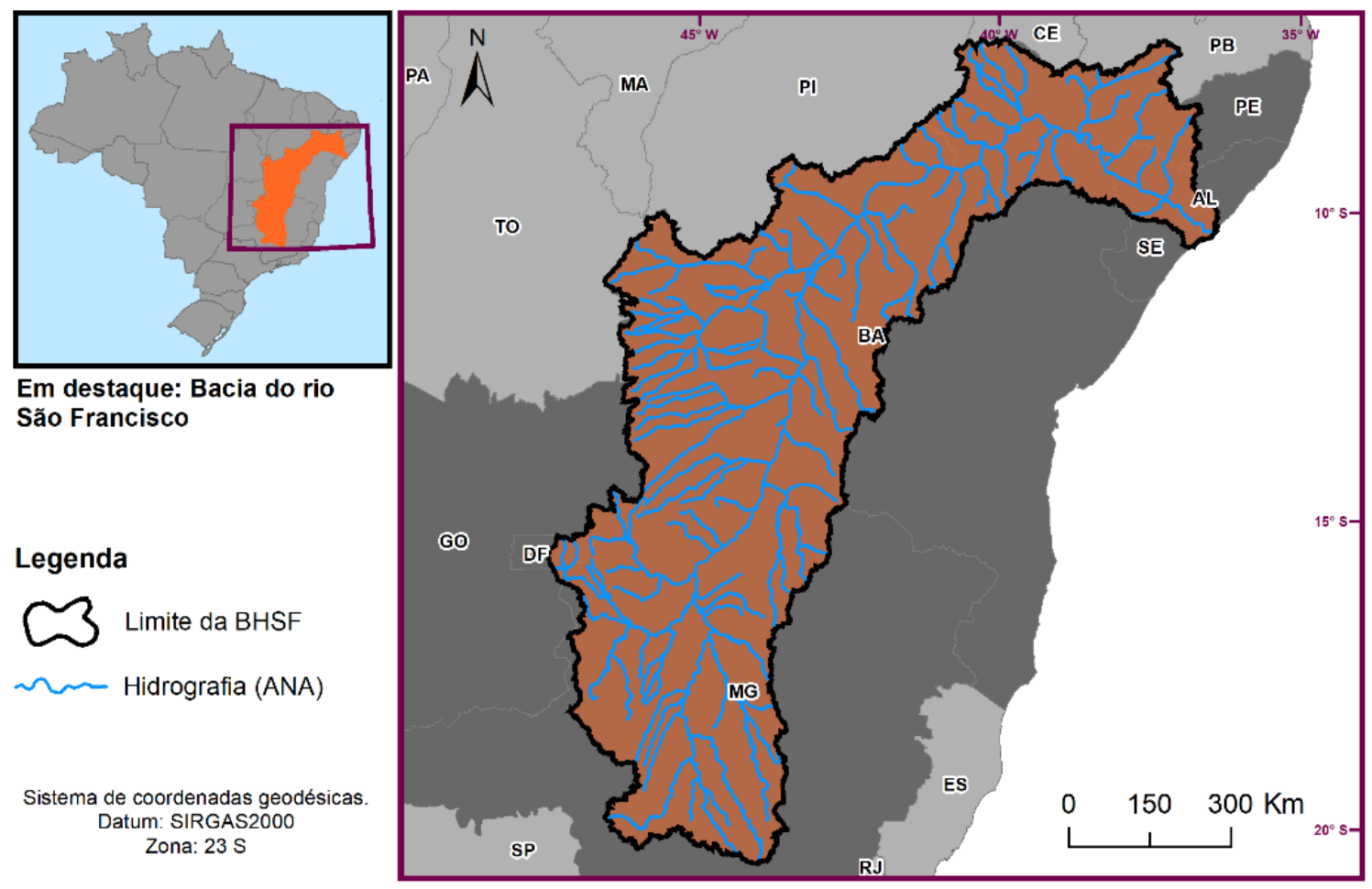

Figura 1: Limite e hidrografia da Bacia do Rio São Francisco

\section{Aquisição e tratamento dos dados}

As análises foram feitas com imagens anuais de 2001 a 2013 com resolução espacial de 500 metros. As imagens de cobertura do solo utilizadas na simulação foram obtidas a partir de produtos gerados pelo sensor MODIS. O MODIS é um instrumento acoplado nas plataformas Terra e Aqua que possui 36 bandas espectrais e gera produtos com resoluções espaciais de 250, 500 e 1000 metros (Teixeira et al., 2020). As imagens foram obtidas através do Reverb ECHO, uma plataforma que disponibiliza diferentes produtos provenientes dos sensores remotos. Para este trabalho foi utilizado o produto MCD12Q1 (Land Cover Type 2) que fornece dados já classificados de cobertura do solo e aborda até 17 classes e 5 tipos de classificações derivadas de um método supervisionado de classificação (National Aeronautics and Space Administration, 2015). As imagens são disponibilizadas pelo sistema sob a forma de "cenas", que consistem em pequenos fragmentos de imagens no formato HDF e projeção Sinusoidal (SIN). Estes fragmentos devem ser posteriormente agrupados, para formar um mosaico que constitui a imagem de trabalho (National Aeronautics and Space Administration, 2015).

Para a realização dos mosaicos de cada um dos anos, foi utilizada a ferramenta MRT (MODIS Reprojection Tool). Essa ferramenta agrupa cenas de imagens provenientes do mesmo tipo de produto que possuem as mesmas dimensões de bandas, mesmo tipo de dado, projeção e resolução espacial (National Aeronautics and Space Administration, 2018). Antes de concluir o mosaico é preciso definir qual tipo de classificação, entre os cinco disponíveis, a imagem final irá receber. Para esse trabalho escolheu-se o esquema de classificação "Tipo 2" que é orientado e supervisionado pela Universidade de Maryland (UMD) nos Estados Unidos (National Aeronautics and Space Administration, 2015). 0 Tipo 2 de classificação possui nível de detalhamento inferior ao do Tipo 1, entretanto contempla todas as classes necessárias para este trabalho. Pode-se citar o fato de o Tipo 1 possuir as classes "gelo e neve", o que para essa simulação não traria nenhum benefício. 0 esquema de classificação utilizado neste trabalho contempla as classes descritas na Tabela 1. 
Com os mosaicos concluídos, as imagens de cada ano foram recortadas utilizando um shapefile do contorno da bacia, de modo que só a área de interesse fosse analisada. Essas manipulações, bem como as transformações geográficas foram realizadas com o auxílio do software ArcGIS 10.2.1.

Tabela 1: Classes de uso do solo correspondentes ao "Tipo 2" de classificação. Fonte: adaptado de National Aeronautics and Space Administration (2015)

\begin{tabular}{c|l}
\hline Código das classes & Descrição \\
\hline $\mathbf{0}$ & Água \\
\hline $\mathbf{1}$ & Floresta perene composta por vegetação aciculifoliada \\
\hline $\mathbf{2}$ & Floresta perene composta por vegetação latifoliada \\
\hline $\mathbf{3}$ & Floresta decidual composta por vegetação aciculifoliada \\
\hline $\mathbf{5}$ & Floresta decidual composta por vegetação latifoliada \\
\hline $\mathbf{6}$ & Floresta mista \\
\hline $\mathbf{7}$ & Área composta por arbustos cujas copas se sobrepõem \\
\hline $\mathbf{8}$ & Área composta por arbustos cujas copas não se sobrepõem \\
\hline $\mathbf{9}$ & Savana Arborizada \\
\hline $\mathbf{1 0}$ & Pastagem \\
\hline $\mathbf{1 2}$ & Vegetação herbácea \\
\hline $\mathbf{1 6}$ & Terras Agrícolas \\
\hline & Área Urbana \\
\hline & Vegetação estéril ou escassa (solo exposto) \\
\hline
\end{tabular}

\section{Dinâmica EGO - Comparação das imagens anuais para a Região Hidrográfica do São Francisco}

Nesse sentido, este trabalho apresenta as principais transições ocorridas no uso do solo entre os anos de 2000 a 2013, em que local ocorreram, qual a natureza das transições e o quanto alterou cada tipo de uso do solo, para toda a extensão da bacia do Rio São Francisco, utilizando dados de MODIS (MCD12Q1 - Land Cover Type 2 Product), com resolução espacial de $500 \mathrm{~m}$.

A contabilização das mudanças anuais do uso e cobertura do solo, bem como a natureza das alterações, foram realizadas através da comparação das imagens Land Cover Tipo 2 através de um algoritmo construído no software DINAMICA-EGO.

O Dinamica EGO é um sistema desenvolvido pelo Centro de Sensoriamento Remoto da Universidade Federal de Minas Gerais. Seu núcleo, responsável pela criação e execução do modelo, é escrito em C++ e sua interface gráfica é escrita em java (Rodrigues et al., 2007; Nti, 2013; SoaresFilho et al., 2007).

O código elaborado no Dinâmica EGO realiza a leitura de duas imagens de entrada de um mesmo local mas em datas diferentes, que possuem a mesma resolução espacial, sejam georreferenciadas e possuam o mesmo tamanho, para avaliar as alterações temporais ocorridas no uso e ocupação do solo. Com as duas imagens de entrada, o sistema permite comparar pixel a pixel por meio da análise dos códigos de uso do solo especificados em cada uma destas imagens. Como resultado dessa comparação, o código gera uma tabela com os códigos e a área, em hectares, de cada transição ocorrida na bacia. Além dos códigos, temos também como saída a geração de mapas que evidenciam as transições de uso e cobertura do solo. Com isso, foi possível quantificar as mudanças ocorridas e avaliar a natureza das alterações através do local onde elas ocorreram.

\section{Vazões médias mensais}

Os dados de vazão utilizados neste trabalho foram coletados do banco de dados da Agência Nacional de Águas - ANA através do Sistema de Informações Hidrológicas - HidroWeb. Foram utilizados dados de 1990 até 2014 com frequência mensal de 18 estações fluviométricas, cujas localizações são mostradas na Figura 2. 


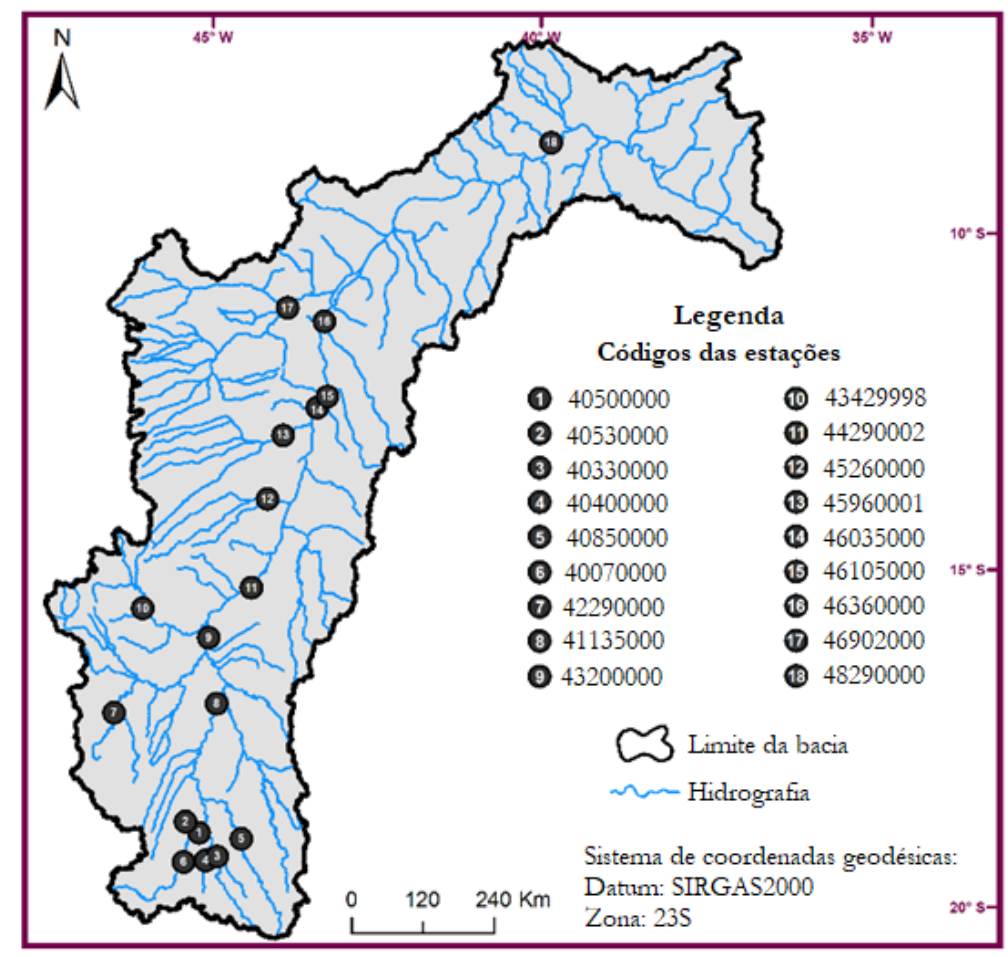

Figura 2: Localização das estações fluviométricas

Os dados das estações fluviométricas possuíam algumas falhas que foram preenchidas, levando em consideração a correlação entre a estação que apresentava falha e as demais estações. A estação que melhor se correlacionava com a que possuía as falhas, considerando apenas as correlações superiores a 0,70 , foi utilizada no processo de preenchimento através de uma equação de regressão linear.

Para realizar as correlações propostas pelo trabalho, as estações fluviométricas foram analisadas por grupos, de acordo com a região em que se encontravam. Desta forma, as estações foram divididas em três grupos da seguinte forma: estações 1, 2, 3, 4, 5, 6 e 8 localizadas do Alto São Francisco, estações 7, 9, 10, 11, 12, 13, 14 e 15 localizadas no Médio São Francisco e estações 16, 17 e 18 localizadas no Submédio e Baixo São Francisco.

Desta forma, os dados mensais de cada estação foram apresentados em um gráfico incluindo também a média das vazões mensais de todas as estações da região de localização. A partir desses dados foram extraídas as máximas vazões mensais de cada região e procedeu-se um cálculo de média simples dessas vazões por década. Os intervalos adotados foram de 1990-1999, 2000-2009 e 2010 a 2014. A partir disto, as informações sobre as médias das vazões máximas por década foram incluídas nos gráficos.

\section{Verificação de tendências}

As análises de tendências estatísticas, para a série histórica de vazões médias mensais para todo o período de estudo (01/1990 a 12/2014), foram realizadas de acordo com o teste de Mann-Kendall. Este é um teste não paramétrico que vem sendo muito utilizado em estudos hidrológicos com o objetivo de avaliar a significância das tendências de variáveis como, precipitação, vazão e qualidade da água (Marengo \& Alves, 2005; Yue et al., 2002; Sagarika et al., 2014).

Este teste estatístico considera uma série temporal do tipo $\mathrm{Xi}, \mathrm{Xi}+1, \ldots, \mathrm{Xn}$ resultante de uma amostra com n variáveis aleatórias independentes e identicamente distribuídas. A estatística do teste de Mann-Kendall (S) é obtida através do somatório dos sinais da diferença entre os valores Xi e os seus valores seguintes, ou seja, $\mathrm{Xj}=\mathrm{Xi}+1$ (Equações 1 e 2). 0 valor de $\mathrm{S}$ positivo indica tendência de aumento, já o valor negativo indica tendência de diminuição. 


$$
S=\sum_{i=1}^{n-1} \sum_{j=i+1}^{n} \operatorname{sinal}\left(X_{j}-X_{i}\right)
$$

Em que:

$$
\operatorname{sinal}\left(X_{j}-X_{i}\right)=\left\{\begin{array}{l}
+1 \operatorname{se}\left(X_{j}-X_{i}\right)>0 \\
0 \operatorname{se}\left(X_{j}-X_{i}\right)=0 \\
-1 \operatorname{se}\left(X_{j}-X_{i}\right)<0
\end{array}\right.
$$

Nos casos em que $\mathrm{n} \geq 10$ a variável $\mathrm{S}$ tende para uma distribuição normal, onde sua variância $(\operatorname{Var}(\mathrm{S}))$ e a variável padronizada (Z) podem ser calculadas por meio das Equações 3 e 4 . Como o teste é bicaudal, a hipótese $\mathrm{H}_{\mathrm{o}}$ (hipótese nula) deve ser rejeitada nos casos em que o valor absoluto de $\mathrm{Z}$ for superior a $Z \alpha / 2$, onde $\alpha$ representa o nível de significância. Neste estudo será considerado um $\alpha$ de $5 \%$ (Yue et al., 2002).

$\operatorname{Var}(S)=\frac{n(n-2)(2 m+5)-\sum_{j=i+1}^{n} t_{j}(i)(i-1)(2 i+5)}{18}$

$Z=\left\{\begin{array}{cc}\frac{S-1}{\sqrt{\operatorname{Var}(S)}} \text { se } S>0 \\ 0 \quad \text { se } S=0 \\ \frac{S+1}{\sqrt{\operatorname{Var}(S)}} \text { se } S<0\end{array}\right.$

A Figura 3 mostra como os procedimentos foram implementados em cada uma das etapas da análise.

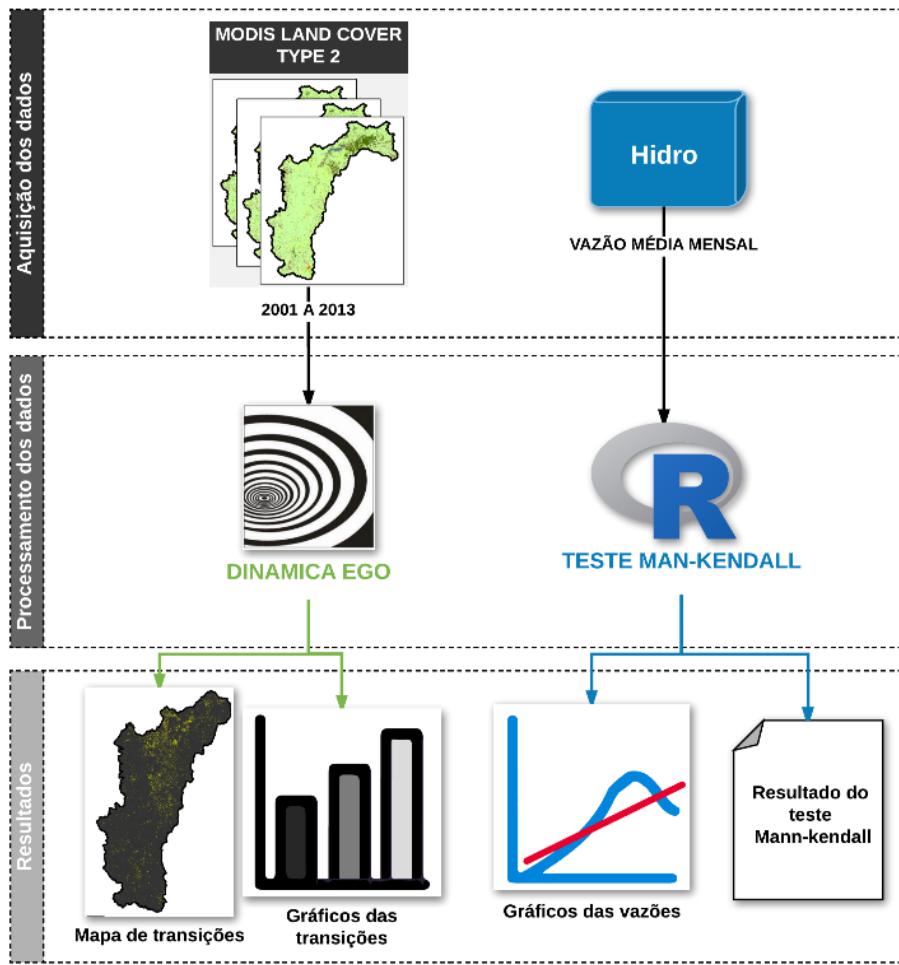

Figura 3: Fluxograma das etapas das análises, contendo do lado esquerdo as etapas de aquisição das imagens, comparação do uso e ocupação do solo e detecção de mudanças no solo. No lado direto as etapas de aquisição de dados hidrológicos, tratamento e análise de tendência pelo teste de Man-Kendal. 


\section{RESULTADOS E DISCUSSÃO}

\section{Teste de Mann-Kendall}

A Figura 4 apresenta o resultado do teste de Mann-Kendall. As estações fluviométricas indicadas em vermelho apresentaram tendência significativa ao nível de $5 \%$, já as estações destacadas em cinza não apresentaram tendência significativa ao nível avaliado. Portanto, 11 das 18 estações estudadas apresentaram tendência decrescente, ou seja, os locais em que essas estações estão instaladas registraram queda na vazão do rio ao longo dos anos. Valença et al. (2015) identificaram redução nas vazões incrementais nos trechos São Francisco/Carinhanha e São Francisco/ Morpará (Médio São Francisco).

Foram selecionadas 3 estações, sendo uma no Alto São Francisco (estação 8 - 41135000), uma no Médio São Francisco (estação 15 - 46105000) e por fim, uma no Submédio São Francisco (estação 18 - 482390000) e analisadas as suas tendências à partir do teste de Mann-Kendall. Com isso, foi definida a área de drenagem para cada estação mencionada, com o intuito de analisar os efeitos das alterações do uso e cobertura do solo para cada estação. As áreas de drenagem e a variação da vazão para cada uma das três estações são apresentadas na Figura 4.

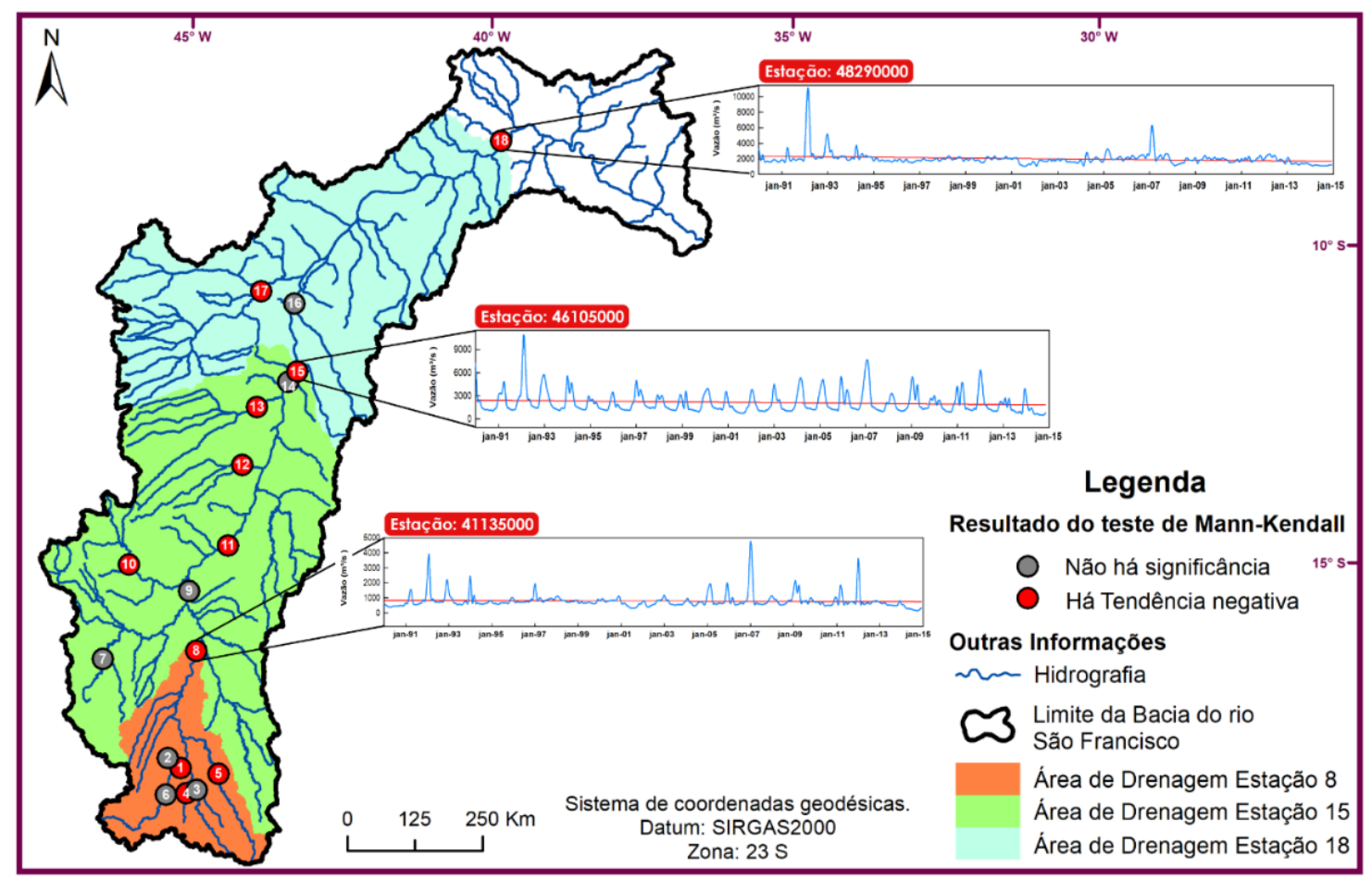

Figura 4: Teste de Mann-Kendall e a área de drenagem gerada para as três estações adotadas

A Figura 5 mostra a variação da vazão ao longo do tempo para cada uma das 11 estações cujos resultados do teste de Mann-Kendall identificaram tendências significativas. Apesar da influência exercida pelos reservatórios no comportamento das vazões, verificou-se, nesse trabalho, a presença de sazonalidade no período analisado. A não estacionariedade da série temporal de vazão foi observada pelos autores Valença et al. (2015). Observou-se no hidrograma de cada uma das 11 estações que todas registraram picos de vazão nos anos de 1992 e 2007, em que o pico de vazão mais expressivo ocorreu no ano de 1992. 


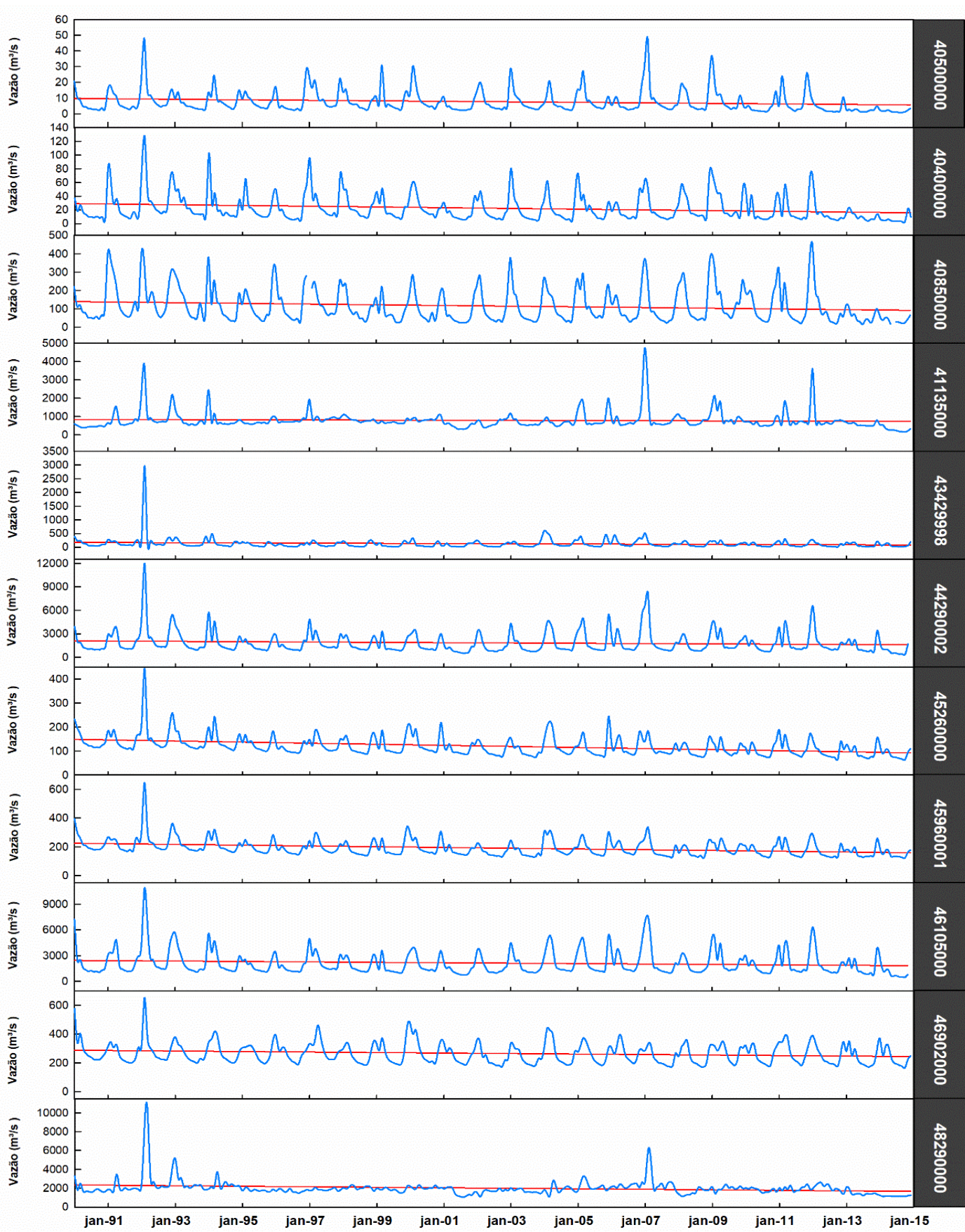

Figura 5: Hidrogramas das 11 estações cujo resultado do teste de Mann-Kendall apontou tendência de diminuição da vazão

\section{Alterações do uso e cobertura do solo na Bacia Hidrográfica do Rio São Francisco}

0 uso predominante do solo na bacia do rio São Francisco é a pastagem, conforme apresentado na Figura 6. É possível observar também que a classe definida por floresta perene composta por vegetação aciculifoliada diminuiu com o passar do tempo para os 13 anos analisados. 


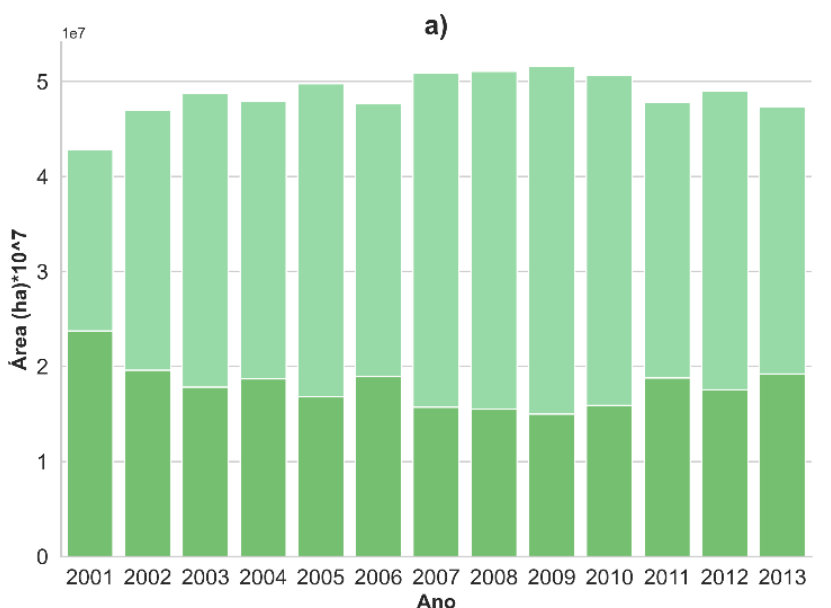

b)

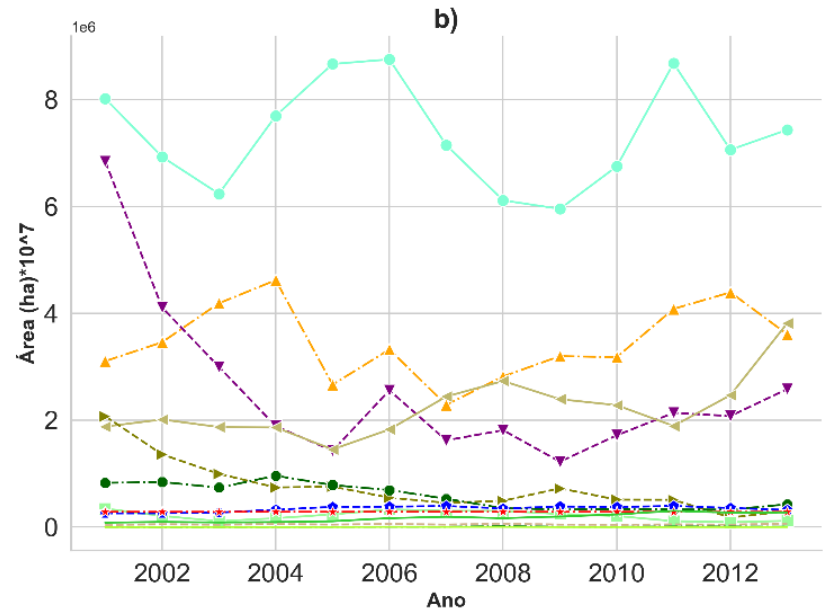

Pastagem Outros usos

Figura 6: Evolução do uso e cobertura do solo de 2001 a 2013 na Bacia Hidrográfica do Rio São Francisco

O algoritmo utilizado no DINAMICA-EGO teve como objetivo analisar todas as combinações de alterações possíveis dentre as classes de uso e cobertura do solo das imagens Land Cover Tipo 2 (MODIS). Com isso, foi possível avaliar as alterações mais significativas ocorridas na região entre os anos de 2001 e 2013. As alterações do uso e cobertura do solo mais expressivas em termos de área convertida e seus respectivos códigos podem ser observados na Tabela 2. A conversão de Florestas, em áreas de Pastagem é a transição mais recorrente na bacia durante o período de estudo. Além disso, é importante destacar que as transições 37 (Savana Arborizada para Terras agrícolas) e 38 (Pastagem para Terras agrícolas) estão diretamente relacionadas ao aumento na demanda hídrica da bacia, e consequentemente, podem interferir no regime de vazões observadas para o Rio São Francisco.

Tabela 2: Alterações mais significativas observadas no uso e ocupação do solo na Bacia do Rio São Francisco

\begin{tabular}{c|c|c}
\hline \multicolumn{1}{c}{$\begin{array}{c}\text { Código da } \\
\text { transição }\end{array}$} & De & Para \\
\hline $\mathbf{1 1}$ & Floresta perene composta por vegetação latifoliada & Pastagem \\
\hline $\mathbf{1 3}$ & Floresta decidual composta por vegetação latifoliada & Pastagem \\
\hline $\mathbf{1 5}$ & Área composta por arbustos cujas copas se sobrepõem & Pastagem \\
\hline $\mathbf{1 7}$ & Savana Arborizada & Pastagem \\
\hline $\mathbf{1 9}$ & Terras Agrícolas & Pastagem \\
\hline $\mathbf{2 7}$ & Savana Arborizada & Vegetação herbácea \\
\hline $\mathbf{2 8}$ & Pastagem & Vegetação herbácea \\
\hline $\mathbf{2 9}$ & Terras Agrícolas & Vegetação herbácea \\
\hline $\mathbf{3 7}$ & Savana Arborizada & Terras Agrícolas \\
\hline $\mathbf{3 8}$ & Pastagem & Terras Agrícolas \\
\hline
\end{tabular}


Na Figura 7, são apresentadas as extensões (em termos de área convertida) para as principais transições citadas na Tabela 2, para as áreas de drenagem das estações fluviométricas 8 (Figura 7a), 15 (Figura 7b) e 18 (Figura 7c). As três áreas de drenagem apresentaram tendência crescente da transição de código 11 (Floresta perene composta por vegetação latifoliada para Pastagem). Além disso, também é possível observar picos de elevação das transições referentes aos códigos 17 e 19, entre
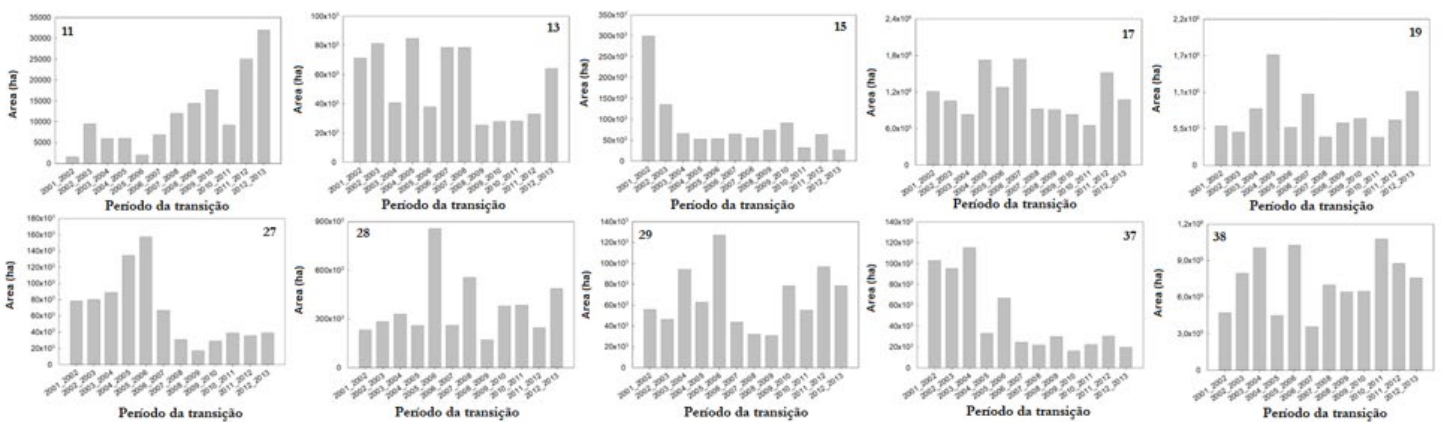

(a)
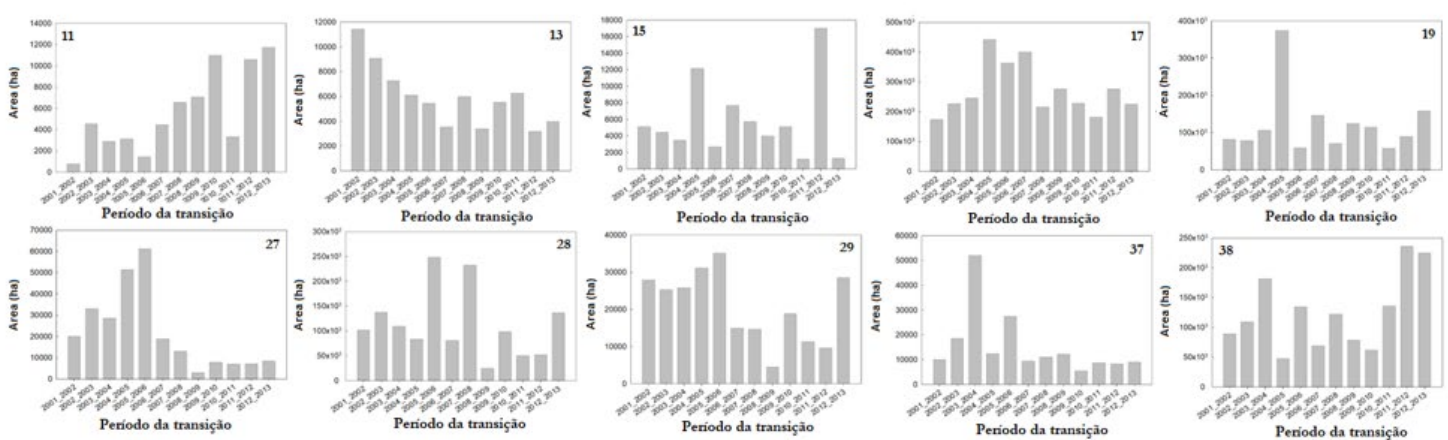

(b)
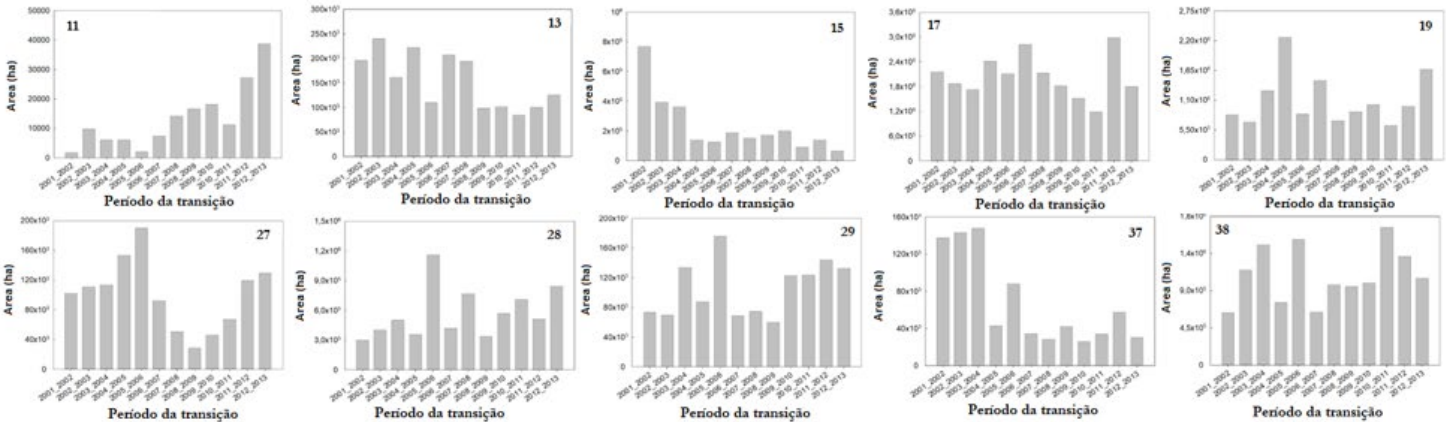

(c)

Figura 7: Transições mais representativas, em termos de extensão, para as áreas de drenagem das estações fluviométricas 8 (a), 15 (b) e 18 (c).

O algoritmo aplicado no software DINAMICA-EGO gera resultados numéricos e mapas que representam as transições ocorridas na bacia. Na Figura 8 é apresentado o desmatamento acumulado para as áreas de drenagem das estações 8 (41135000), 15 (46105000) e 18 (48290000). A partir deste resultado é possível observar que, para as três áreas de drenagem estudadas, o desmatamento mais intenso ocorre nas proximidades dos cursos d'água. Portanto, a diminuição da vazão observada nas estações da Figura 5 pode ser explicada e relacionada à elevada presença de atividades de irrigação na bacia, que representa cerca de $77 \%$ da vazão outorgada da região (Brasil, 2015). 


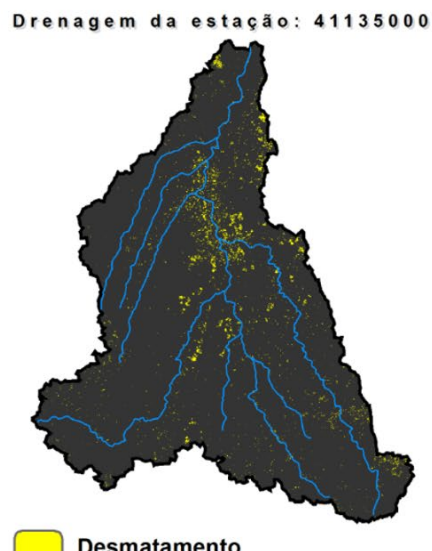

Desmatamento

(a)

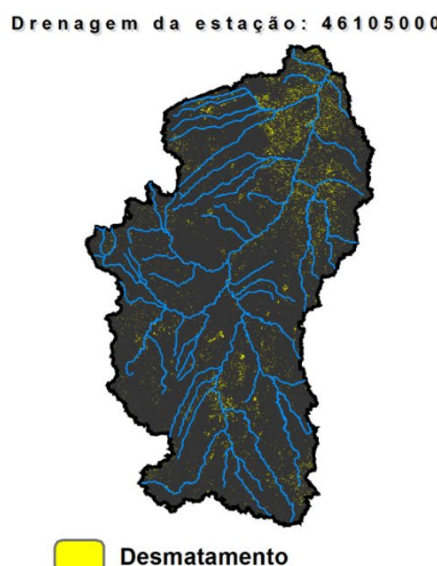

(b)

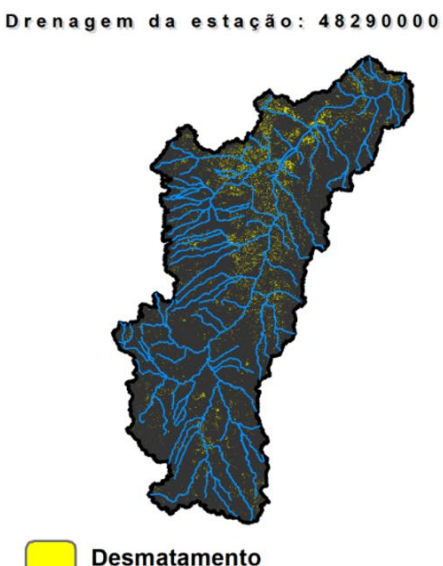

(c)

Figura 8: Desmatamento ocorrido nas áreas de drenagem das estações fluviométricas 8 (a), 15 (b) e 18 (c) no período compreendido entre os anos 2001 e 2013.

De acordo com o Relatório do Comitê da Bacia Hidrográfica do rio São Francisco a irrigação foi responsável por um aumento de 114\% na demanda hídrica da região entre os anos de 2000 e 2013 (Comitê da Bacia Hidrográfica do Rio São Francisco, 2016). Na Tabela 3 são apresentados os principais usos da água na BHRSF e a evolução das demandas com o passar dos anos, entre 2000 e 2010. Nota-se um aumento da demanda em praticamente todos os setores (exceto abastecimento rural), no entanto, os recursos hídricos destinados a abastecer as atividades de irrigação foram os que apresentaram o maior crescimento percentual para o período estudado.

Tabela 3: Evolução das demandas hídricas na Bacia do Rio São Francisco. Fonte: Plano de Recursos Hídricos da Bacia Hidrográfica do Rio São Francisco (Comitê da Bacia Hidrográfica do Rio São Francisco, 2016).

\begin{tabular}{c|c|c|c}
\hline \multirow{2}{*}{ Setor } & \multicolumn{3}{c}{ Vazão de retirada $\left(\mathbf{m}^{3} / \mathbf{s}\right)$} \\
\cline { 2 - 4 } & $\mathbf{2 0 0 0}$ & $\mathbf{2 0 0 6}$ & $\mathbf{2 0 1 0}$ \\
\hline Abastecimento urbano & 26,0 & 27,3 & 31,3 \\
\hline Abastecimento rural & 3,8 & 3,7 & $244,4^{*}$ \\
\hline Irrigação & 114,0 & 123,3 & 10,2 \\
\hline Criação animal & 6,7 & 9,1 & 19,8 \\
\hline Abastecimento industrial & 15,3 & 17,4 & 309,4 \\
\hline Total & 165,8 & 180,8 & \\
\hline
\end{tabular}

*valor referente ao ano de 2013

Na Figura 9 estão representadas as áreas agrícolas e suas demandas outorgadas no ano de 2014. Observou-se que na região oeste a área de drenagem da estação 18, localizada no submédio São Francisco, há uma concentração de áreas irrigadas com elevado consumo de água, quando comparado às outras regiões (Figura 9c). Além disso, os resultados das alterações do uso e cobertura do solo apontaram uma predominância de novas terras agrícolas (Figura 9d). Estas novas transições ocorreram na mesma região onde as demandas por irrigação são mais elevadas. Portanto, os resultados apontam novamente para a relação direta entre a diminuição das vazões, aumento da demanda hídrica pela atividade de irrigação e consequente aumento de terras convertidas em áreas agricultáveis. 

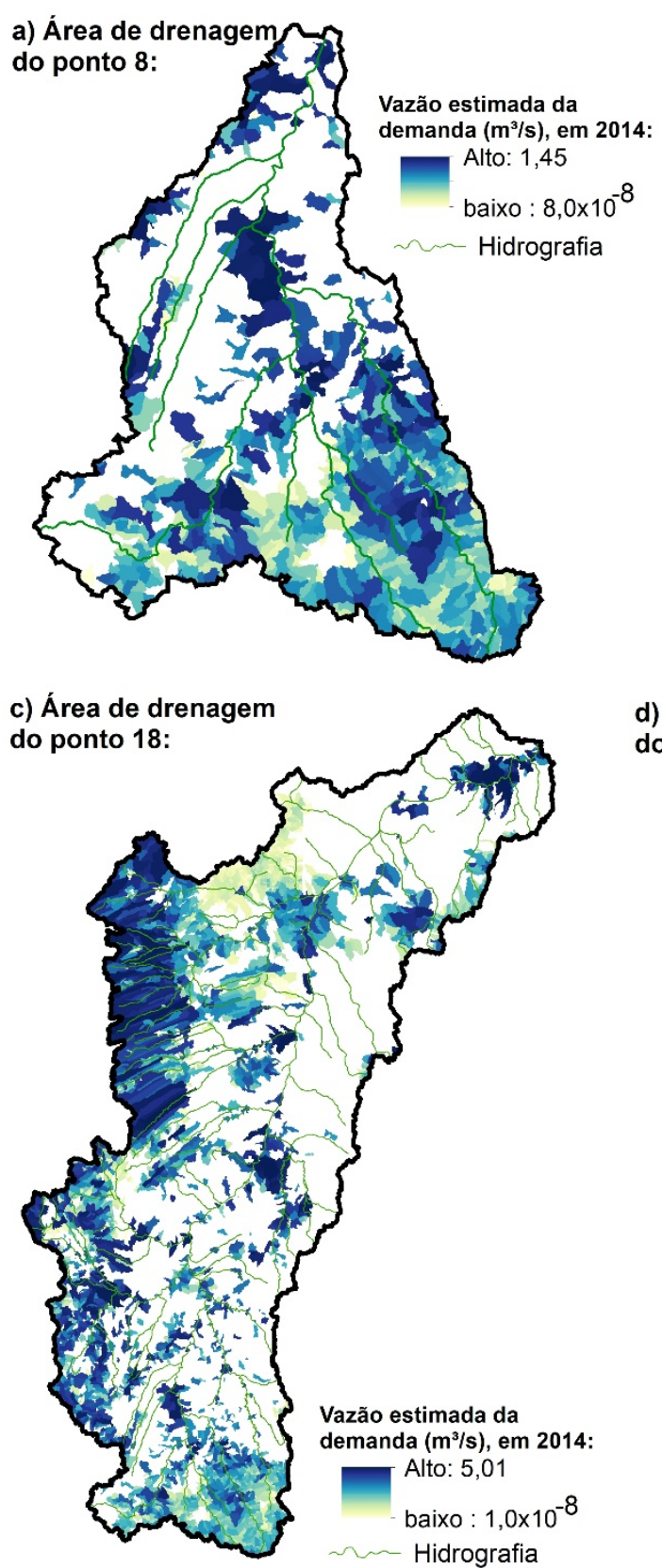

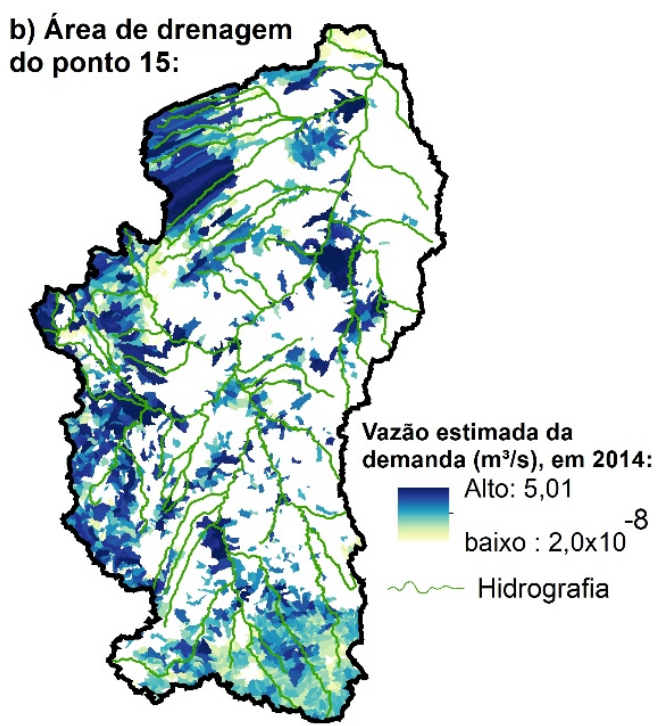

d) Área de drenagem dos pontos 8, 15 e 18:

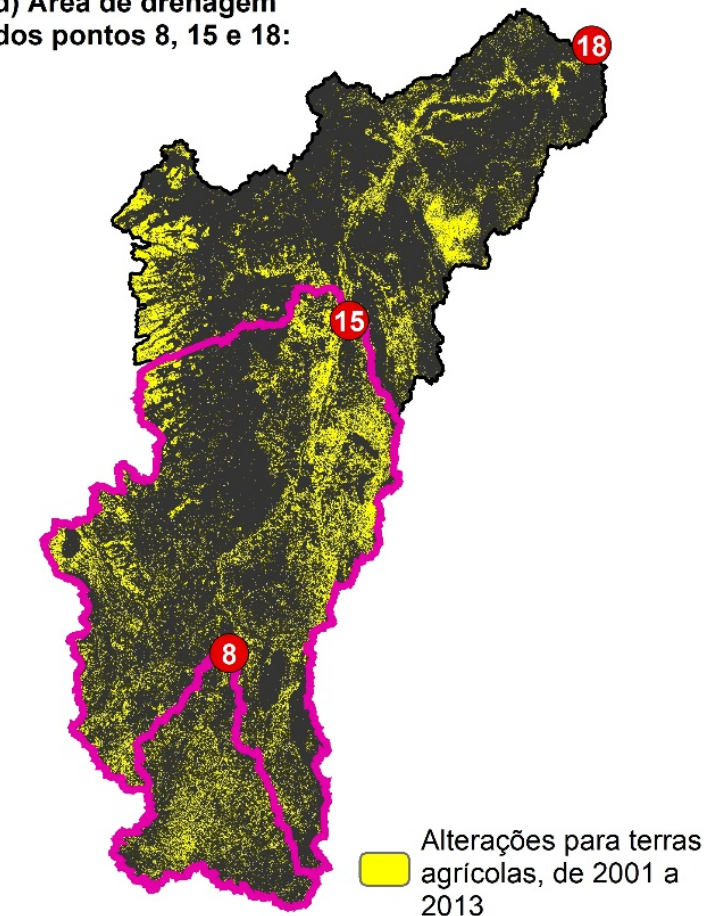

Figura 9: Vazão estimada da demanda hídrica para atividades de irrigação no ano de 2014 para as áreas de drenagem das estações fluviométricas 8 (a), 15 (b) e 18 (c), e novas terras convertidas em áreas agrícolas no período compreendido entre os anos 2001 e 2013. Fonte: Brasil (2015).

Resultados semelhantes foram obtidos por outros autores para a mesma região de estudo. Silva et al. (2018) encontrou uma diminuição nos índices de vegetação no município de Petrolina (PE), localizado na região do Baixo São Francisco, entre os anos de 2013 e 2015. Santos et al. (2014) avalia o impacto das atividades antrópicas na vegetação nativa de mangue da região no ano de 2008. Os autores puderam concluir que parte das áreas de mangue podem ter sido convertidas com o objetivo de desenvolver atividades de agricultura e aquacultura na região. Já no estudo desenvolvido por Koch et al. (2015), dois cenários diferentes foram analisados para a BHRSF: o primeiro se trata de um cenário em que o crescimento econômico é moderado, o crescimento populacional é alto e onde as práticas de sustentabilidade não são bem aplicadas; o segundo cenário é mais otimista em que se tem um crescimento populacional moderado, elevado crescimento econômico e excelentes práticas ambientalmente sustentáveis. Os resultados desta pesquisa apontam que, para o primeiro cenário apresentado, as áreas agrícolas iriam dobrar do ano de 2005 para o ano de 2035, substituindo a vegetação natural presente na região. Entretanto, para o cenário mais otimista, as áreas agrícolas iriam 
permanecer com a mesma extensão que se apresentam atualmente, permitindo maior conservação das áreas nativas.

Os sistemas irrigados localizados na Bacia Hidrográfica do São Francisco interferem não somente nas alterações do uso do solo, mas também no regime de vazões e na disponibilidade hídrica para os demais usos na bacia. Por outro lado, a própria agricultura irrigada sofre com a falta de solos ricos, ineficiência estratégica de gestão dos recursos hídricos, além de dificuldade na inclusão de pequenas propriedades na estrutura do sistema de irrigação (Siegmund-Schultze et al., 2018). Maneta et al. (2009) quantificaram a demanda hídrica dos projetos de ampliação da área irrigada na Bacia Hidrográfica do São Francisco e avaliaram o efeito dessa expansão nas vazões do rio. Os autores concluíram que as regiões de Barreiras e de Juazeiro/Petrolina, por exemplo, que possuem alto potencial de desenvolvimento de culturas irrigadas, podem contribuir para a diminuição da disponibilidade hídrica à jusante. $\mathrm{Na}$ análise, os autores também concluíram que o aumento da irrigação na região provocou uma redução no aporte de água para barragem de Sobradinho. 0 monitoramento da vazão afluente à barragem mostrou que, nos meses mais secos, houve uma redução de $90 \mathrm{~m}^{3} / \mathrm{s}$ em relação à vazão média observada para o mesmo período. Já para os meses úmidos, a redução chega à $122,2 \mathrm{~m}^{3} / \mathrm{s}$. Esses valores são alcançados pois, durante o período chuvoso, as áreas plantadas são mais extensas e a chuva não é bem distribuída, portanto a demanda hídrica sofre elevação. Os autores também avaliaram as alterações na vazão à jusante da barragem de Sobradinho e concluíram que uma redução de até $505 \mathrm{~m}^{3} / \mathrm{s}$ pode ser alcançada nos períodos de estiagem. Santos et al. (2020) avaliaram o impacto das alterações do uso do solo nas vazões observadas na região do Baixo São Francisco, entre os estados de Sergipe e Alagoas no período compreendido entre 2013 e 2018. Os autores identificaram dois tipos de área com diferentes comportamentos na região: um corresponde à uma área com solo mais homogêneo e que apresenta maior preservação ambiental (localizada mais a oeste); e o segundo tipo é representado por uma área mais heterogênea, com frações de solo exposto e elevada degradação ambiental (localizada mais a leste). Os resultados apontam que as atividades de irrigação e pastagem localizadas nas áreas mais degradadas da bacia são responsáveis pelo aumento da vulnerabilidade ambiental do local, uma vez que impulsionam o processo de assoreamento dos cursos d'água. Além disso, os autores também observam uma diminuição na área superficial ocupada pelo corpo d'água de 2013 para 2018. Esse fenômeno está associado à crescente implantação de perímetros irrigados na bacia aliado à evaporação que já ocorre nos reservatórios.

Desta forma, é possível observar uma contínua e intensa alteração no uso do solo na Bacia Hidrográfica do São Francisco no início do séc. XXI e um aumento da vazão captada para atender às áreas irrigadas. Além disso, há evidências de que o aumento da demanda hídrica para irrigação possa estar gerando uma redução na vazão observada na bacia. Através dos processos de modelagem e previsão abordados na literatura, nota-se que a tendência atual é de ampliação dos perímetros irrigados e, consequentemente, maior processo de alteração do uso do solo. No entanto, os impactos decorrentes dessas alterações podem vir a ser minimizados através da aplicação de práticas sustentáveis, que atendam às necessidades e exigências ambientais, juntamente com uma gestão integrada e responsável dos recursos hídricos.

\section{CONCLUSÃO}

A Bacia do Rio São Francisco passou por um intenso processo de transformação do uso do solo entre os anos 2001 e 2013. Neste trabalho, foram detectadas alterações significativas relacionadas à conversão de Florestas em áreas de Pastagem e de Savanas arborizadas e Pastagens em Terras agrícolas. Além disso, as transições descritas como Savana Arborizada para Terras agrícolas e Pastagem para Terras agrícolas estão diretamente relacionadas com o aumento da demanda hídrica na região devido a operação e expansão dos sistemas de irrigação.

Desta forma, pode-se inferir que o elevado desenvolvimento agrícola na bacia do São Francisco pode estar diretamente relacionado com as alterações nas vazões observadas nessa região, no período analisado. Estes resultados podem ser confirmados através do teste de Mann-Kendall, que mostra que 11 estações fluviométricas, das 18 analisadas, apresentaram dados de vazões médias mensais com tendência de queda.

Os autores recomendam a realização de estudos futuros com objetivo de analisar a influência dos reservatórios. Assim, espera-se que este trabalho possa contribuir para um planejamento adequado e uma melhor gestão dos recursos hídricos da Bacia hidrográfica do Rio São Francisco, uma vez que as alterações do uso e cobertura do solo podem interferir diretamente no regime de vazões médias mensais da região. 


\section{REFERÊNCIAS BIBLIOGRÁFICAS}

Bezerra, B. G., Silva, L. L., Silva, C. M. S., \& Carvalho, G. G. (2019). Changes of precipitation extremes indices in São Francisco River Basin, Brazil from 1947 to 2012. Theoretical and Applied Climatology, 135(1), 565-576.

Boëchat, I. G., Paiva, A. B. D. M. D., Hille, S., \& Gücker, B. (2013). Land-use effects on river habitat quality and sediment granulometry along a 4th-order tropical river. Revista Ambiente \& Água, 8(3), 54-64.

Brasil. Agência Nacional de Águas - ANA. Superintendência de Planejamento de Recursos Hídricos - SPR. Conjuntura dos recursos hídricos no Brasil: regiões hidrográficas brasileiras. Brasília. DF: Agência Nacional de Águas 2015.

Comitê da Bacia Hidrográfica do Rio São Francisco - CBHSF. (2016). Plano de recursos hídricos da bacia hidrográfica do rio São Francisco 2016-2025. Recuperado em 9 de março de 2021, de https://cbhsaofrancisco.org.br/plano-de-recursos-hidricos-da-bacia-hidrografica-do-rio-sao-francisco/

Costa, E. P., Pinto, C. C., Soares, A. L. C., Melo, L. D. V., \& Oliveira, S. M. A. C. (2017). Evaluation of violations in water quality standards in the monitoring network of São Francisco River basin, the third largest in Brazil. Environmental Monitoring and Assessment, 189(11), 1-16.

Foley, J. A., Defries, R., Asner, G. P., Baford, C., Bonan, G., Carpenter, S. R., Chaplin, F. S., Coe, M. T., Daily, G. C., Gibbs, H. K., Helkowski, J. H., Holloway, T., Kucharik, C. J., Monfreda, C., Patz, J. A., Prentice, I. C., Ramankutty, N., \& Snyder, P. K. (2005). Global consequences of land use. Science, 309(5734), 570-574.

Instituto Brasileiro de Geografia e Estatística - IBGE. (2010). Censo 2010. Rio de Janeiro: IBGE. Recuperado em 9 de março de 2021, de https://censo2010.ibge.gov.br/

Instituto Brasileiro de Geografia e Estatística - IBGE. Coordenação de Recursos Naturais e Estudos Ambientais. (2013). Manual técnico de uso da terra (3. ed.). Rio de Janeiro: IBGE.

Koch, H., Biewald, A., Liersch, S., Azevedo, J. R. G., Silva, G. S., Kölling, K., Fischer, P., Koch, R., \& Hattermann, F. F. (2015). Scenarios of climate and land-use change, water demand and water availability for the São Francisco River Basin. Brazilian Journal of Environmental Sciences, 36, 96-114.

Maneta, M. P., Torres, M., Wallender, W. W., Vosti, S., Kirby, M., Bassoi, L. H., \& Rodrigues, L. N. (2009). Water demand and flows in the São Francisco River Basin (Brazil) with increased irrigation. Agricultural Water Management, 96(8), 1191-1200.

Marengo, J. A., \& Alves, L. M. (2005). Tendências hidrológicas da bacia do rio Paraíba do Sul. Revista Brasileira de Meteorologia, 20(2), 215-226.

Mello, K., Taniwaki, R. H., Paula, F. R., Valente, R. A., Randhir, T. O., Macedo, D. R., Leal, C. G., Rodrigues, C. B., \& Hughes, R. M. (2020). Multiscale land use impacts on water quality: assessment, planning, and future perspectives in Brazil. Journal of Environmental Management, 270, 110879.

National Aeronautics and Space Administration - NASA. (2015). MCD12Q1 - MODIS/Terra+Aqua Land Cover Type Yearly L3 Global 500 m SIN Grid. Recuperado em 9 de março de 2021, de https://lpdaac.usgs.gov/products/mcd12q1v006/

National Aeronautics and Space Administration - NASA. (2018). User guide to collection 6 MODIS land cover (MCD12Q1 and MCD12C1) product. Recuperado em 9 de março de 2021, de https://lpdaac.usgs.gov/documents/101/MCD12_User_Guide_V6.pdf

Nti, I. K. (2013). Geospatial process modelling for land use cover change (Tese de doutorado). School of Computing and mathematical Sciences, Auckland University of Technology, New Zealand.

Pinheiro, A., Schoen, C., Schultz, J., Heinz, K. G. H., Pinheiro, I. G., \& Deschamps, F. C. (2014). Relação entre o uso do solo e a qualidade da água em bacia hidrográfica rural no bioma Mata Atlântica. Revista Brasileira de Recursos Hídricos, 19, 127-139.

Reis, P. A. G., Fontes, A. S., \& Medeiros, Y. D. P. (2020). Definição da vazão de contribuição como estratégia de gestão na bacia hidrográfica do Rio São Francisco. Revista de Gestão de Água da América Latina, 17(21), e21.

Rodrigues, H. O., Soares-Filho, B. S., \& Costa, W. L. S. (2007). Dinamica EGO, uma plataforma para modelagem de sistemas ambientais. In Anais do XIII Simpósio Brasileiro de Sensoriamento Remoto (pp. 3089-3096). Florianópolis, SC.

Sagarika, S., Kalra, A., \& Ahmad, S. (2014). Evaluating the effect of persistence on long-term trends and analyzing step changes in streamflows of the continental United States. Journal of Hydrology, 517, 36-53.

Santos, A., Lopes, P. M. O., Silva, M. V., Jardim, A. M. R. F., Moura, G. B. A., Fernandes, G. S. T., Silva, D. A. O., Silva, J. L. B., Rogrigues, J. A. M., Silva, E. A., \& Oliveira-Júnior, J. F. (2020). Causes and consequences of Seasonal 
changes in the water flow of the São Francisco river in the semiarid of Brazil. Environmental and Sustainability Indicators, 8, 100084.

Santos, L. C. M., Matos, H. R., Schaffer-Novelli, Y., Cunha-Lignon, M., Bitencourt, M. D., Koedam, N., \& DahdouhGuebas, F. (2014). Anthropogenic activities on mangrove areas (São Francisco River Estuary, Brazil Northeast): A GIS-based analysis of CBERS and SPOT images to aid in local management. Ocean and Coastal Management, 89, 39-50.

Siegmund-Schultze, M., Köppel, J., \& Sobral, M. C. (2018). Unraveling the water and land nexus through inter-and transdisciplinary research: sustainable land management in a semi-arid watershed in Brazil's northeast. Regional Environmental Change, 18(7), 2005-2017.

Silva, D. A. O., Silva, J. L. B., Silva, T. S. S., Santos, P. R., Lopes, I., \& Santos, C. G. (2018). Impacto da alteração do uso do solo usando dados orbitais no baixo São Francisco. Revista Ambientale, 10(3), 71-85.

Silva, V. D. P., Silva, M. T., \& Souza, E. P. D. (2016). Influence of land use change on sediment yield: a case study of the sub-middle of the São Francisco River basin. Journal of the Brazilian Association of Agricultural Engineering, 36(6), 1005-1015.

Soares Filho, B. S., Cerqueira, G. C., Araújo, W. L., \& Voll, E. (2007). Modelagem de dinâmica de paisagem: concepção e potencial de aplicação de modelos de simulação baseados em autômato celular. Megadiversidade, 3(1-2), 74-76.

Sriwongsitanon, N., \& Taesombat, W. (2011). Effects of land cover on runoff coefficient. Journal of Hydrology, 410, 226-238.

Teixeira, A. H. D. C., Takemura, C. M., Leivas, J. F., Pacheco, E. P., Bayma-Silva, G., \& Garçon, E. A. (2020). Water productivity monitoring by using geotechnological tools in contrasting social and environmental conditions: Applications in the São Francisco River basin, Brazil. Remote Sensing Applications: Society and Environment, 18, 100296.

Valença, M., Holz, J., \& Kirillos, D. (2015). A água do Rio São Francisco está sumindo. In Anais do XXI Simpósio Brasileiro de Recursos. Brasília.

Yue, S., Pilon, P., \& Cavadias, G. (2002). Power of the Mann-Kendall and Spearman's rho tests for detecting monotonic trends in hydrological series. Journal of Hydrology, 259(1-4), 254-271.

\section{Contribuições dos autores:}

Bruna Thomazinho França: trabalhou no tratamento de imagens de sensoriamento remoto e detecção de mudanças de uso e ocupação do solo a partir de imagens MODIS. Trabalhou também na interpretação dos dados elaboração do texto.

Marcel Pereira de Andrade: trabalhou na análise estatística de dados de vazão. Trabalhou também na interpretação dos dados e elaboração das figuras do texto.

Celso Bandeira de Melo Ribeiro: trabalhou supervisionando toda a parte de tratamento dos dados desde a obtenção de imagens e séries temporais de dados de vazão até as análises e tratamento dos dados. Trabalhou também na interpretação dos resultados, elaboração do texto final do manuscrito.

Henrique Steinherz Hippert: trabalhou dando suporte à toda a parte de tratamento estatístico dos dados 